\title{
Using A Web-Based Supply Chain Management Simulation As An Experiential Learning Tool Across The Business Curriculum
}

Russell Haines, (Email: rhaines@odu.edu), Old Dominion University Jill Hough, (Email: Jill-hough@utulsa.edu), University of Tulsa

Douglas Haines, (Email: dhaines@uidaho.edu), University of Idaho Scott Metlen, (Email: metlen@uidaho.edu), University of Idaho

\begin{abstract}
A web based version of the common "Beer Distribution Game" that facilitates experiential learning was developed and tested for use across the business curriculum. While the fundamental elements of the original paper based game were preserved, the web-based on-line multiplayer version offers refinements to game play, administration and debriefing that allow more focus on the learning experience and open possible applications beyond the traditional one-time demonstration of the bullwhip effect. The web-based supply chain management simulation was tested and refined in Strategic Management courses and Integrated Business Curriculum courses at two widely separated universities. Students responded favorably to the on-line simulation and were very willing to reflect on what they learned about how they made decisions, how worked under conditions of uncertainty, how they treated information and how they worked in the supply chain environment. The simulation can be used to demonstrate systems thinking and various other concepts throughout the business school curriculum including courses in Operations Management, Strategy, Information Systems, and Marketing.
\end{abstract}

\section{INTRODUCTION}

n the spirit of experiential learning through role playing activities in the classroom, we present a web-based
version of the common "Beer Distribution Game." We argue that this web-based version better fulfills the
objectives of experiential learning than the original paper-based version. In particular, this revised approach
results in a better understanding of the world we live in where that understanding results in greater critical thinking
and problem solving skills (Dewey, 1933; Hickcox, 2002). The non-web version of the beer game has, to some
degree, demonstrated a messy business problem labeled the "bullwhip effect" to thousands of business students over
the course of forty plus years. The web-based version we present here better demonstrates the bullwhip effect and its
associated effects in the current technologically enhanced environment and can thus better fulfill experiential learning
objectives.

The bullwhip effect occurs as small variations in demand at the retail level produce increasing levels of order variability as we move up through each layer of the supply chain toward the factory, or producer, who is the first member of the supply chain (Lee et al 1997). Supply chain inefficiencies such as distorted information and mistrust from one end of the supply chain to the other create a messy business problem driven by the bullwhip effect. The results of the bullwhip effect are lost revenue, lost profit, and lost trust, with high inventories and excess capacity at some supply chain entities while other entities are providing poor customer service due to stockouts. The increase in variability is demonstrated in Figure 1 reproduced from Lee et al (1997). The classic example of such behavior is the 
extreme fluctuation in orders for disposable diapers experienced by Procter and Gamble despite relatively flat demand at the retail level.

Figure 1 The Bullwhip Effect
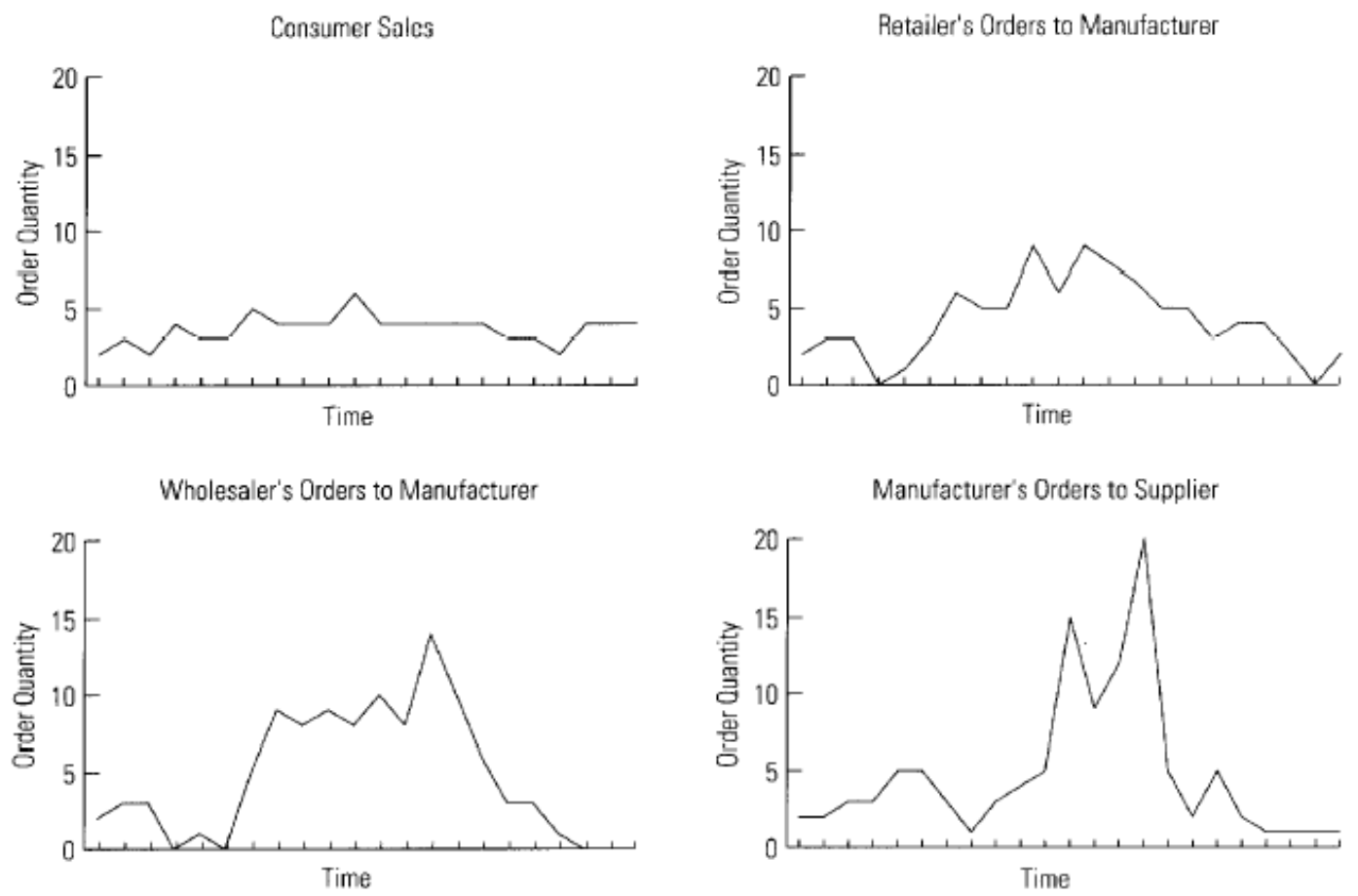

THE BEER GAME

The beer game is an example of experiential learning through role-playing. The game or "simulation" was developed at MIT in the 1960s and has been used extensively in education settings to demonstrate supply chain behavior, cognitive limitations to rationality, systems theory, and numerous other lessons in management science (Goodwin \& Franklin 1994; Simchi-Levi et al, 1999; Sterman 1989). In the game, players experience the role of a retailer, wholesaler, distributor, or factory in a prototypical supply chain where each entity is isolated from the others except for orders and deliveries. Retailers attempt to meet consumer demand, wholesalers attempt to fill orders from the retailer, and so on. The traditional version of the game is played on a large table that is divided into sections for each of the four positions in the supply chain. Cases of product are represented as pennies or chips that are produced at the factory, distributed through the supply channel, and finally "delivered" to consumers. The objective of the game is to minimize total backlog plus inventory costs. After the game is played, instructors debrief the game. Sterman (1989) and Senge (1990) have detailed descriptions of how the traditional game is played.

Kolb (1984) postulates that students learn from four different perspectives, that is by (1) experiencing events, (2) reflecting on those experiences, (3) conceptualizing what was experienced, and (4) testing what was learned against their current schema. As evidenced by the game's continual success over a time span of over 40 years, the traditional game and debriefing, helped students learn from each of the four perspectives.

It is during this debriefing that students are given a chance to reflect on what they have experienced, conceptualize the experience, and compare what they have learned to their current knowledge base to test whether the 
message learned from the experience makes sense to their world. Students reflect as they review what happened during the game to them and others. As they conceptualize, students use principles and theories from appropriate disciplines to make sense out of what happened throughout the learning activity and to explain their reactions to the experience. Specific to the beer game, students use principles and theories from business and psychology to determine what caused the escalating order variation and to explain their reaction to the game. Students then test their learning by taking the principles learned from the debriefing and determining if those principles would hold up in the world they know (Kolb, 1984).

While the game has been successful since its design, supply chain management has improved. The use of advanced operations management techniques and information systems suggests that the beer game, as traditionally played, does not reflect current supply chain practices (Simchi-Levi et al 1999) and therefore may not provide a learning experience that can be generalized to current real world situations. Student comments suggest that when they test the outcome of the game against the wired world they know, they do not believe that the problems encountered during the game will be encountered in the real world due to the capability of modern communication technology. Another weakness of the traditional beer game is the amount of "overhead" associated with rules and record keeping causing students to focus on the mechanics of the game rather than contemplating the system dynamics. Furthermore, playing the traditional beer game for 36 weeks takes longer than the typical business school class time of 75 minutes, forcing lecturers to cut the simulation short and/or dedicate a longer class period to play and debriefing.

One alternative to the traditional beer game is the single player "Computerized Beer Game" (Simchi-Levi et al 1999). It was designed specifically to address many of the weaknesses of the traditional game by allowing customizable computer players to manage positions in the supply chain using well-defined ordering rules, offering customizable demand patterns, providing options for information availability that reflect advances in data interchange, and offering flexibility in order delays to reflect JIT strategies. However, this single-player game has some significant limitations when compared with the traditional game: 1) computer players are not bound by the cognitive nature of humans so they are more consistent and usually perform better than human players (Sterman 1989), and 2) the interaction with numbers on a screen rather than physical objects as a representation of product (e.g., pennies) reduces the perception of order magnitude and inventory buildup that form the tangible artifacts of the bullwhip effect.

\section{WEB-BASED VERSION}

We designed and developed a web-based (i.e., on-line), multi-player version of the beer game to help mitigate problems with the traditional board game through the use of computers in the classroom while at the same time retaining and enhancing the behavioral aspects that are lost in the single player computerized game. First, student players occupy all positions within the supply chain when possible (computer players are used when less than four student players are available), leading to significant variability in performance through the reintroduction of human cognition. Second, representations of cases on-screen show the massive amounts of inventory and orders that exist in the supply chain.

A web-based platform was chosen rather than a client-server platform to allow for 1) easy administration because there is no special software to download and install, 2) the largest simultaneous number of students to participate, limited only by the capacity of the network and server(s) and 3) the potential for geographically dispersed game play just as members of a supply chain are dispersed. Administration of the game is also web-based, allowing games to be set up from any computer with a browser and Internet connection.

The web-based beer game includes all of the features of the board game with some display differences (see Figure 2). A single bullet (•) on the screen represents a case of product, allowing the students to count the "cases" when determining their order. Bullets are in groups of five, which eases the task of counting somewhat, but is similar to the procedure used by players in the traditional game. When necessary, larger bullets represent "pallets" of 50 cases, which conveys the magnitude of the delivery or inventory level while allowing the students to quickly add up large inventory levels. 
Figure 2: Game Screen

\begin{tabular}{|c|c|c|c|c|c|c|c|c|c|}
\hline \multicolumn{4}{|c|}{ Week 4} & \multicolumn{6}{|c|}{ Distributor's Record Sheet: } \\
\hline \multicolumn{4}{|c|}{ Retailer } & \multirow[b]{2}{*}{ Week } & \multirow{2}{*}{\multicolumn{2}{|c|}{$\begin{array}{c}\text { Your } \\
\text { Inventory }\end{array}$}} & \multirow[b]{2}{*}{$\begin{array}{l}\text { Your } \\
\text { Cost }\end{array}$} & \multirow{2}{*}{\begin{tabular}{|c|} 
Wholesaler \\
ordered
\end{tabular}} & \multirow{2}{*}{\begin{tabular}{|l} 
You \\
ordered \\
from \\
Factory
\end{tabular}} \\
\hline$<-$ & Shipped to Consumer & $<\left|\begin{array}{c}\text { Current Inventony } \\
\ldots-. . . . . . . . .\end{array}\right|<-$ & $\begin{array}{l}\text { Shipment Arrives in } 1 \text { Wue el(s) } \\
\text {.... }\end{array}$ & & & & & & \\
\hline \multicolumn{4}{|c|}{ Wholesaler } & 3 & & 12 & $\$ 6.00$ & 4 & 4 \\
\hline$<-$ & $\begin{array}{c}\text { Shipped to Retailer } \\
\text {.... }\end{array}$ & $<\mid \begin{array}{c}\text { Current Inventony } \\
<-. . . . . . . . . .\end{array}$ & $\begin{array}{c}\text { Shipment Arrives in } 1 \text { Week(s) } \\
\text {.... }\end{array}$ & 2 & & 12 & $\$ 6.00$ & 4 & 4 \\
\hline \multirow{2}{*}{\multicolumn{4}{|c|}{ Distributor }} & 1 & & 12 & $\$ 6.00$ & 4 & 4 \\
\hline & & & & \multicolumn{3}{|c|}{ Total Cost: } & \multicolumn{3}{|c|}{$\$ 18.00$} \\
\hline \multicolumn{4}{|c|}{$\begin{array}{c}\text { Incoming Order } \\
4\end{array}$} & & & & & & \\
\hline$<-$ & \begin{tabular}{|c|} 
Shipped to Wholesaler \\
...
\end{tabular} & $<-\mid$ Current Inventong $<$ <- & \begin{tabular}{|c|} 
Shipment Arrives in 1 Wieek(s) \\
....
\end{tabular} & & & & & & \\
\hline \multicolumn{4}{|c|}{ Factory } & & & & & & \\
\hline \multirow[t]{4}{*}{$<-$} & \begin{tabular}{|c|} 
Shipped to Distributor \\
$\ldots . .$.
\end{tabular} & $<\left|\begin{array}{c}\text { Current Inventony } \\
\ldots . . . . . . . . . .\end{array}\right|<-$ & $\begin{array}{c}\text { Production Finished in } 1 \text { Whe elss } \\
\ldots . .\end{array}$ & & & & & & \\
\hline & & & $\wedge$ & & & & & & \\
\hline & & & \begin{tabular}{|c|} 
Production Finished in 2 Wheet(s) \\
$\ldots . .$.
\end{tabular} & & & & & & \\
\hline & & Your order & for Week 4: & mit Ord & & & & & \\
\hline
\end{tabular}

The orientation of the items on the screen was designed to make the game play and experience as similar as possible to the board game. However, the orientation of the supply chain was switched to a vertical rather than horizontal orientation so that it would fit in a browser window with the on-screen representation of the record sheet. To allow players to see the results of the most recent week without having to use the scroll bars on their web browsers, entries on the record sheet are ordered such that the most recent orders appear first. In addition, the orders that a player ships downstream in the current period are placed in that player's section rather than in the downstream supplier's section. This provides feedback as to how much product the player is able to ship that week without the movement of product. Finally, all references to "beer" and "game" were removed to mitigate any potential framing effects regarding industry or games of chance. Thus, the game is referred to as "The Distribution System Simulation."

To better mimic supply chains, several different demand patterns are available, including traditional beer game pattern where demand jumps from 4 cases to 8 cases per week (44448888 ...), slow growth (4444555555666...), small step $(44446666 \ldots . .$.$) , and tiny step (444455555 \ldots)$. Information availability can also be customized to provide players with: 1) reported consumer demand for each period, and/or 2) backlog amounts, which are given as negative numbers. One of the rules of the original game was that there was to be no communication between the different players of the supply chain. This rule mimics traditionally non-communicative supply chains and generally leads to a greater bullwhip effect. When students of today test such a game rule against what they know about their own environment, they are more likely to attribute the bullwhip effect solely to lack of communication rather than to variables of human cognition.

\section{COURSE APPLICATIONS}

The simulation can be used to demonstrate various concepts throughout the business school curriculum including courses in Operations Management, Strategy, Information Systems, and/or Marketing. For example, the bullwhip effect can be discussed in the context of organizational and process design where capitalization and control of human cognition is the goal. Furthermore, some effects of price promotions can be demonstrated in Marketing 
courses; systems thinking and behavioral decision making can be demonstrated in Management courses; and transaction costs and vertical integration can be discussed in Strategic Management courses.

We conducted sessions in two Strategic Management classes at a private Midwestern university and four Integrated Business Curriculum classes at a public Northwestern university. The sessions were conducted in a 40 seat classroom computer lab (Midwestern university) and two 60 seat classrooms where students used their own laptops (Northwestern university). Students were allowed to seat themselves, and told to set their web browser address to the URL of the main game page. After receiving instructions on-line and completing pre-simulation questionnaires regarding personality traits and decision making processes, each player was randomly assigned to a supply chain. When the class size is not a multiple of four, computer players are assigned to the open positions in the last supply chain.

Once assigned to a supply chain, participants completed the same familiarizing period as the board game in which players order four cases for three weeks. This process allowed familiarity with the game and the display. Beginning with week four, players were allowed to order any nonnegative quantity they wished. Students were told the simulation would run for 52 simulated weeks, but as in the board game, play was halted after 36 weeks. The "early" end to the simulation prevents endplay by participants. Because the $100 \%$ demand increase of the traditional game (from four to eight) has been criticized as unrealistic (Riddalls \& Bennett, 2002; Simchi-Levi et al 1999), we used a "small step" in demand, where the jump is from four to six (a $50 \%$ increase).

During the simulation, students placed their order for the week then waited for all other participants in their supply chain to place their orders before the week was processed and evaluated. After all students had experienced 36 weeks of transactions across their supply chain, the other three learning perspectives (reflecting, conceptualizing and testing) were initiated. Without looking to see what the actual demand increase was, each student filled in a web form with their estimate of weekly retail demand for each of the 36 weeks. Students whose games finished earlier than others were allowed to 1) browse information about their responses to the online personality questionnaire that was administered prior to the start of the simulation, 2) view graphs that compared their after-the-fact demand predictions, actual order amounts, and inventory levels, and/or 3) see how their total costs compared to other groups.

Once all of the supply chains in the session were finished, the final evaluation was made and small prizes were awarded to the supply chains with the lowest total costs. (At most one supply chain in each session contained computer players. As expected, these teams usually performed the best because the computer players used a consistent order rule. Students on these teams received a token prize along with the best all student team.) It took approximately one hour to complete the entire game including the pre- and post-simulation questionnaires regarding personality traits, decision-making processes, trust, etc., leaving five minutes at the beginning of a 75 minute class for latecomers and about ten minutes at the end for discussion. The actual 36 week game was completed by all teams in less than 25 minutes.

To demonstrate that bull whip effects are not just generated by lack of communication, but by human cognition, one-quarter of the games had the demand information on their record sheets, one-quarter had the backorder quantities shown, one-quarter had both demand information and backorder quantities shown, and the remaining mimicked the original board game where the entities did not have either demand or backorder information. During the discussion, students were asked to comment on whether knowing demand or knowing backorders helped to eradicate the bullwhip effect.

\section{OBSERVATIONS FROM CLASSROOM APPLICATION}

Students generally responded favorably to the on-line game. Although some of the students were familiar with the computerized single-player game, this previous familiarity did not improve their performance. Confirming that human cognition often overpowers communicated information, students reported that knowing demand did not make a difference in their performance. Some students commented that they assumed the information was bad information possibly because their myopic view of demand for the system did not fit the displayed information. For 
the most part, students said they did not account for the supply line, although some said that knowing the backlogs in the supply chain made a difference and helped them to make better decisions.

Having a smaller step in demand (50\% increase) still led to a significant oscillation in almost all of the supply chains, similar to what has been observed in the traditional game with the doubling of demand. When asked, students said that a smaller step (25\% increase) would also lead to similar results. The lessons of the simulation concerning the effect of human cognition on decision making, whether related to supply chain management, price promotions, systems thinking, behavioral decision-making, or other relevant objectives, are more powerful when oscillations are observed even under such conditions of relatively stable external forces.

The speed of the game can certainly be accelerated by elimination of the pre- and post- simulation questionnaires, which took approximately 25 minutes. In addition, speed may be improved through additional up-front familiarization and/or having computer players fill one or more roles in every supply chain. Shortening the time of the game will also give more time for reflection, conceptualization and testing, deepening the learning experience (Silberman, 1996).

Lowering the initial inventory level from twelve to eight (or even lower) would probably help familiarization. At a level of twelve, some students attempt to reduce their inventory first, leading to bullwhip effects even before demand increases. Furthermore, with an initial inventory of twelve, it is possible to simply match incoming orders and never have inventory drop below zero at any point on the supply chain, even when demand doubles from four to eight. A starting inventory level of four would give each player one week of safety stock. However, it may be beneficial to start with five to highlight the difference between starting inventory and the initial (i.e. required) order of four.

The additional feature most requested by the students was to be able to "chat" with other members of their supply chain. Allowing this would remove one of the most important rules in the traditional game where no talking is allowed and a communication provision would most likely add significantly to the amount of time required for the simulation. However, experiences in real-world supply chains indicate that communication alone would not mitigate the bullwhip effect and other lessons of the beer game (Hammond 1994).

\section{LIMITATIONS OF THE WEB-BASED GAME}

The primary limitation of the web-based game is also present in the computerized single-player game: it is difficult to duplicate the mechanics of transferring physical inventory, or passing pennies/chips, on the computer screen. The passing of the physical object serves two objectives. First, it communicates that a quantity of product is being passed through the supply chain. Second, it reinforces the role of the player as a member of a supply chain. Students playing the web-based game had trouble with both aspects. During the familiarization period, they had trouble grasping that they had actually filled an order and that cases of product were actually moving through the chain. This replicates the world of the purchasing agent and buyer who seldom actually see the product. They also did not seem to fully understand the relationship between the amount that was ordered from their downstream partner and the amount that was shipped. An obvious way to communicate this information would be to have varying amounts of initial inventory at each stage of the supply chain, but this would add variability to the chain and reduce the likelihood that students would notice the steady demand for the first four weeks. The computerized single-player game attempts to communicate this on the order screen by showing the order that was received, any backorders, and the amount that was shipped.

\section{CONCLUSIONS}

The web-based distribution simulation offers a facilitated learning experience for students and instructors that maintains and enhances the well-tested attributes of the traditional beer game. The simulation also allows facilitates learning objectives in areas such as systems thinking, supply chain management, and the effects of human cognition in systems performance with reduced administrative burden for both instructors and students. In addition, because the computer deals with record keeping issues, students may be more attentive to application of principles than to concern 
for record keeping. Furthermore, instructors can present this learning opportunity with less preparation and execution time, and devote more class time to the important learning perspectives of reflection, conceptualization, and testing. With the options currently in place, simulation administrators have additional flexibility to change key factors such as patterns of demand and information provided to participants to suit their particular learning objectives. The fundamental simulation presented here provides a solid foundation for more complex and realistic simulations by building-in more options and additional flexibility.

For access to the web-based Supply Chain Management Simulation Experiential Learning Tool contact Russell Haines, Old Dominion University, rhaines@odu.edu.

\section{References}

1. Chen, Fangruo. Decentralized Supply Chains Subjects to Information Delays. Management Science. 45 (8). August 1999. pp. 1076-1090

2. Dewey, J. How we Think. Boston: D. C. Heath, 1933.

3. Goodwin, Jack S. and Stephen G Franklin. The Beer Distribution Game: Using Simulation to Teach Systems Thinking. The Journal of Management Development, 13 (8), 1994 pp 7-15

4. Hammond, Janice H. Barilla SpA Harvard Business School Case 9-694-046 1994.

5. Hickcox, Leslie. Personalizing Teaching through Experiential Learning. College Teaching, 50 (4), 2002.

6. Kolb, D. A. Experiential Learning: Experience as the Source of Learning and Development. Englewood Cliffs, NJ: Prentice-Hall, 1984.

7. Lee, Hau L., V. Padmanabhan, and Seungjin Whang. The Bullwhip Effect in Supply Chains. Sloane Management Review. 38 (3). Spring 1997. pp. 93-102

8. Riddalls, C. E. and S. Bennett. The Stability of Supply Chains. International Journal of Production Research. 40 (2). 2002. pp. 459-475

9. Senge, Peter. The Fifth Discipline: The Art and Practice of the Learning Organization. Currency Doubleday, 1990.

10. Silberman, Mel. Active Learning: 101 Strategies to Teach Any Subject. Allyn and Bacon, Boston, 1996.

11. Simchi-Levi, D., P. Kaminsky and E. Simchi-Levi, Designing and Managing the Supply Chain: Concepts, Strategies and Case Studies, Irwin/McGraw-Hill, 1999.

12. Sterman, John D. Modeling Managerial Behavior: Misperceptions of Feedback in a Dynamic Decision Making Experiment. Management Science. 35 (3). March 1989. pp. 321-339 


\section{NOTES}

